\title{
INTEGRAÇÃO DE DADOS GPS DE DIFERENTES PRECISÕES MEDIANTE A TÉCNICA DE REDES NEURAIS ARTIFICIAIS PARA A GERAÇÃO DE MDT
}

\author{
Elaine Cristine Barros de Souza ${ }^{1}$ \\ Cláudia Pereira Krueger ${ }^{2}$ \\ Selma Regina Aranha Ribeiro ${ }^{2}$ \\ Mosar Faria Botelho ${ }^{3}$
}

\begin{abstract}
Resumo: O objetivo deste estudo é mostrar uma alternativa para a integração de dados GPS de precisões diferentes, visando uma Modelagem Digital do Terreno (MDT). Os levantamentos GPS foram realizados através do posicionamento relativo e da técnica cinemática, utilizando-se observações de fases das portadoras $L_{1}$ e $L_{2}$, ou apenas da portadora $\mathrm{L}_{1}$, e do código C/A. As precisões obtidas com o pós-processamento destes levantamentos foram de ordens centimétricas $(\approx 20 \mathrm{a} 50 \mathrm{~cm})$ e métricas $(\approx 1 \mathrm{a} 3 \mathrm{~m})$, respectivamente. A metodologia proposta baseou-se no uso de técnica de integração usando-se algoritmo de Redes Neurais Artificiais (RNA). Foram realizadas análises qualitativas (isolinhas e MDT) e quantitativas (resíduos).
\end{abstract}

A metodologia foi avaliada: 1) pelas análises do comportamento da grade gerada com o algoritmo de interpolação convencional Inverso do Quadrado de uma Distância (IQD) frente aos levantamentos e 2) por pontos de verificação coletados na superfície do terreno. O método testado mostrou-se viável comparativamente com o algoritmo IQD. Portanto, a RNA apresentou-se apta para a interpolação e integração de dados GPS de diferentes precisões.

Palavras-chave: Interpolação, integração, GPS, Redes Neurais Artificiais (RNA)

\begin{abstract}
The objective of this study is to show an alternative for the interpolation and integration of GPS data of different precisions, aiming a Digital Terrain Modeling (DTM). GPS surveying data were obtained using relative positioning with kinematic technique, using the phases of the $L_{1}$ and $L_{2}$ carriers, or only with $L_{1}$ carrier phase, and the use of the C/A-code observations. The precisions obtained with the post-processing of the GPS surveying data are in the centimetric $(\approx 20$ up to $50 \mathrm{~cm})$ and metric $(\approx 1$ up to $3 \mathrm{~m})$ orders, respectively. The proposed methodology was based on integration technique using Artificial Neural Networks (ANN) algorithm. The results were tested by means of analyses of the behavior of the gridding generated with the conventional interpolation algorithm Inverse Square Distance (ISD), which was adopted as the reference model for the comparisons among methods. Qualitative (isolines and DTM) and quantitative (residuals) analyses were accomplished and comparisons with the gridding generated by the ANN in the interpolation stage and integration of the GPS data were done. The tested method was shown viable in comparison with the ISD algorithm. In conclusion RNA was showed able for the interpolation and integration of GPS data of different precisions.
\end{abstract}

\footnotetext{
${ }^{1}$ Universidade Federal do Paraná - UFPR - elainecbsouza@hotmail.com

${ }^{2}$ Universidade Federal do Paraná - UFPR - Departamento de Geomática - (ckrueger, selmar@ufpr.br)

${ }^{3}$ Universidade Federal do Paraná - UFPR -mfbotelho@yahoo.com.br
} 
Keywords: Interpolation, integration, GPS, Artificial Neural Networks (ANN) 


\section{INTRODUÇÃO}

A partir do século XX com o advento das técnicas empregadas em Geodésia, e Cartografia, bem como análises matemáticas e estatísticas, atreladas à evolução dos computadores, foi possível mapear amplas áreas com elevado grau de precisão. As ações e os projetos envolvendo temas que agregam informações relacionadas com a superfície do terreno, devem estar apoiados por uma base geodésica e por uma cartografia de qualidade. O Global Positioning System (GPS), é um exemplo de um componente eficaz para a formação de uma base geométrica uniforme.

Diante da elevada importância do GPS nos dias atuais, torna-se necessária à realização de estudos que permitam investigar 0 comportamento dos levantamentos efetuados com diferentes receptores (fabricantes), diferentes técnicas de posicionamento empregadas, sob diferentes épocas e constelações (satélites) e diferentes áreas (relevos), com o intuito de integrar o maior número de informações possíveis, visando despertar nos profissionais que utilizam o sistema o interesse não apenas na aquisição de informações para um posicionamento preciso, mas também na sua integração, permitindo a geração de sub-produtos de qualidade, como por exemplo, os modelos tridimensionais de superfícies.

Desde o surgimento do GPS, muitas questões foram levantadas sobre ele, a maioria com intuito de aprimorá-lo, na tentativa de explorar todas as suas potencialidades. Nesse contexto, algumas perguntas podem ser formuladas: seria possível fazer com que dados GPS coletados através de receptores que utilizam diferentes portadoras, por exemplo, $\mathrm{L}_{1} \mathrm{~L}_{2}, \mathrm{~L}_{1}$ e o Código, numa mesma área, sob a mesma ou diferente constelação de satélites, porém com diferentes caminhamentos percorridos, possam ser "interpolados" e também "integrados" de forma a se obter um nível de precisão ideal para geração de Modelos
Digitais do Terreno (MDT) com qualidade e conseqüentemente precisão? Outra pergunta: seria possível modelar essas diferenças de precisões, ponderá-las de forma que a pior precisão não interfira na melhor ou vice-versa? E uma última pergunta surge: qual método ou técnica seria a mais adequada para este estudo e como avaliar se os resultados obtidos foram satisfatórios? O intuito deste trabalho é tentar responder essas perguntas.

Assim, neste trabalho, é apresentada uma metodologia para interpolar e combinar/integrar dados provenientes de levantamentos GPS. A metodologia é avaliada, efetuando a comparacao dos resultados do método convencional não estocástico de interpolação, o algoritmo Inverso do Quadrado de uma Distância (IQD) com aquele da Rede Neural Artificial (RNA) comparando os desempenhos quanto a interpolação e integração dos dados GPS de diferentes precisões, bem como a modelagem tridimensional, mediante análises qualitativas (isolinhas e o MDT) e quantitativas (resíduos) a partir das grades geradas, por ambos os métodos.

\section{MATERIAL}

\section{1. Área de Estudo}

A área escolhida para a realização do levantamento de campo (coleta dos dados GPS), localiza-se no Campus Centro Politécnico da Universidade Federal do Paraná (UFPR), área cercada, representada na Figura 1, que se encontra atrás do Laboratório de Geodésia Espacial (LAGE), que possui as RRNN, com coordenadas Universal Transverse Mercator (UTM) no Sistema de Referência WGS-84, sendo as altitudes (H) geométricas: RN01 (N:7184247,916m; $\quad$ E:677881,479m; H:925,223m), RN02 (N:7184210,177m; E:677900,403m; H:924,459m), RN03 (N:7184210,009m; $\quad$ E:677856,723m; H:923,785m) e a estação PARA (N:7184223,247m; $\quad$ E:677878,526m; 
H:925,759m), a qual faz parte da Rede Brasileira de Monitoramento Contínuo (RBMC) de responsabilidade do Instituto Brasileiro de Geografia e Estatística (IBGE).

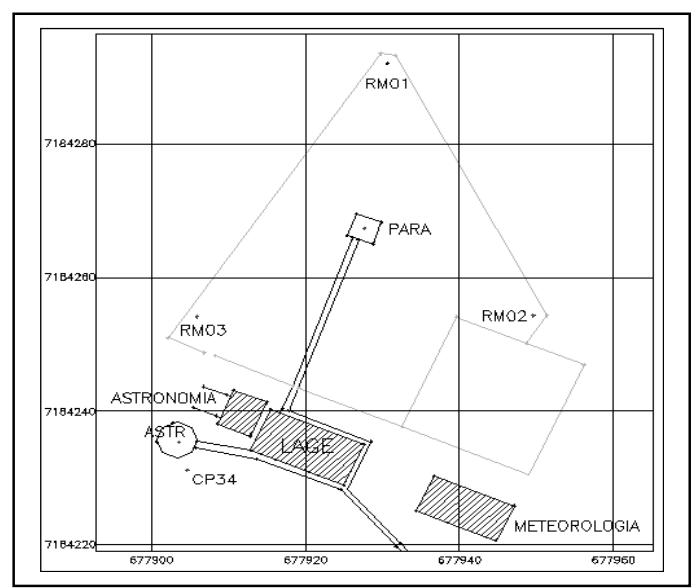

Figura 1 - Área teste e disposição das RRNN

\section{METODOLOGIA}

Com a finalidade de avaliar a qualidade da interpolação e integração usando a RNA, a metodologia foi dividida em etapas, que são: Coleta de dados, geração de uma grade pelo método convencional de interpolação (IQD), geração da grade pela RNA e avaliação do desempenho da RNA na interpolação e integração de dados GPS de diferentes precisões, ainda identificar e comparar as diferenças entre as técnicas empregadas.

\subsection{Levantamentos de Campo}

Os levantamentos de campo consistiram em levantamentos, utilizando o método de posicionamento relativo e a técnica cinemática com uma taxa de coleta dos dados de 1s.

No primeiro levantamento, realizou-se um caminhamento de forma a cobrir toda a área, utilizando um receptor Ashtech ZXII (12 canais), com portadoras $\mathrm{L}_{1} \mathrm{~L}_{2}$ e seus acessórios. No segundo levantamento, utilizou-se um receptor Ashtech Reliance (12 canais) com portadora $\mathrm{L}_{1}$ e o Código (CA) e seus acessórios, só que neste caminhamento apenas uma porção da área foi levantada. ENGEVISTA, v. 8, n. 1, p. 27-36, junho 2006
O terceiro e último levantamento consistiu de outro caminhamento, só que utilizando um receptor Ashtech Z-XII (12 canais), com portadoras $\mathrm{L}_{1} \mathrm{~L}_{2}$ e Código (CA) e seus acessórios, só que usando apenas o Código.

Este levantamento foi realizado somente numa porção da área. A Figura 2 ilustra os caminhamentos para os três levantamentos e pode-se visualizar as RRNN que estão contidas em cada um dos levantamentos.

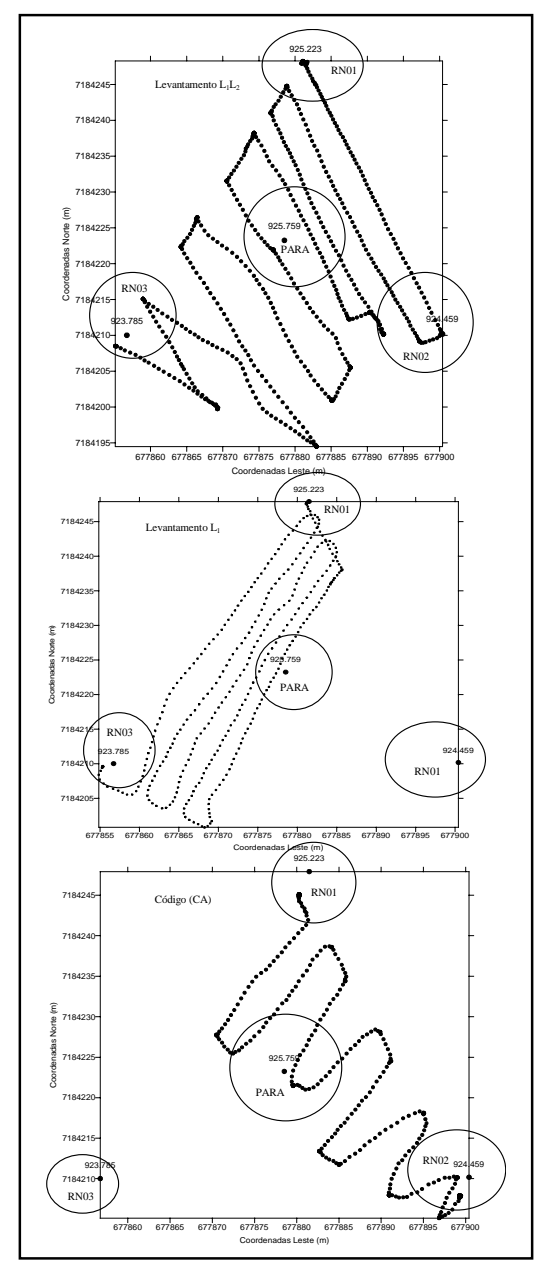

Figura 2 - Caminhamentos percorridos

O pós-processamento dos dados, forneceu precisões relativas da ordem centimétrica ( $\approx 20$ a $50 \mathrm{~cm}$ ), e um total de 890 elementos amostrais para o levantamento usando as portadoras $\mathrm{L}_{1} \mathrm{~L}_{2} \mathrm{e}$ 344 usando $L_{1}$. A precisão obtida com 0 
Código - CA foi de (1 a 3m) para um total de 444 coordenadas coletadas.

\subsection{Geração do Modelo pelo Interpolador IQD}

Tendo as coordenadas planimétricas 1678 pares de coordenadas $(\mathrm{E}, \mathrm{N}) \mathrm{e}$ altitudes (H) (em UTM/WGS-84), obtidas do pós-processamento dos dados GPS (posicionamento relativo e técnica cinemática - portadoras $\mathrm{L}_{1} \mathrm{~L}_{2}, \mathrm{~L}_{1} \quad \mathrm{e}$ Código). A primeira etapa para a obtenção das isolinhas e do MDT e posteriores análises, consistiu na geração de uma grade regular com o uso do interpolador IQD.

Utilizou-se uma resolução para a geração da grade, de $1 \mathrm{~m} \times 1 \mathrm{~m}(\mathrm{E}, \mathrm{N})$, respectivamente. Este valor foi estabelecido partindo-se da coleta dos dados GPS que foi realizada com uma taxa de 1s com o usuário se deslocando a uma velocidade média de $5 \mathrm{~km} / \mathrm{s}$, assumindo então, uma distância entre os pontos de aproximadamente $1 \mathrm{~m}$. A grade de referência foi interpolada, com o algoritmo IQD, implementado no software Surfer.

Segundo SOUZA (2002), esse método de interpolação é o que melhor representa e modela uma área quando são realizadas análises qualitativas e quantitativas, fazendo uso de dados pontuais oriundos de levantamentos GPS, pelo fato dele utilizar um critério de ponderação nas coordenadas.

As análises qualitativas serão mediante as isolinhas e o MDT. E as análises quantitativas serão realizadas avaliando a diferença entre a grade gerada e $30 \%$ de pontos de verificação, os quais não fizeram parte no processo de geração da grade.

Foi verificado nas primeiras grades geradas, que a área levantada sofre uma "extrapolação" para toda a grade, "mascarando" de certa forma, a verdadeira área a ser modelada/representada. Diante desse problema, foi criado os chamados arquivos blanked ou vazios, os quais possibilitam delimitar a área de interesse dentro da grade gerada para posterior análises. De posse então da nova área delimitada, foi realizada uma nova interpolação, utilizando os mesmos critérios anteriores e gerando como saída uma nova grade a qual permitiu representar com mais fidelidade à área em estudo, isto é, a trajetória percorrida sem qualquer extrapolação na grade.

Essa análise é importante não apenas para visualização, mas principalmente para que se possa posteriormente efetuar o cálculo dos resíduos, para avaliação da precisão dos mesmos os quais dependem da grade gerada. Desta forma, na análise deve-se considerar apenas a área de interesse sem qualquer extrapolação, fornecendo resultados confiáveis, buscando informações mais significativas/reais. A grade gerada foi de 55 linhas por 47 colunas. As Figuras 3 e 4 mostram o resultado do processamento da grade, mediante a geração das isolinhas e do MDT, bem como a trajetória percorrida nos três levantamentos e a localização das RRNN.

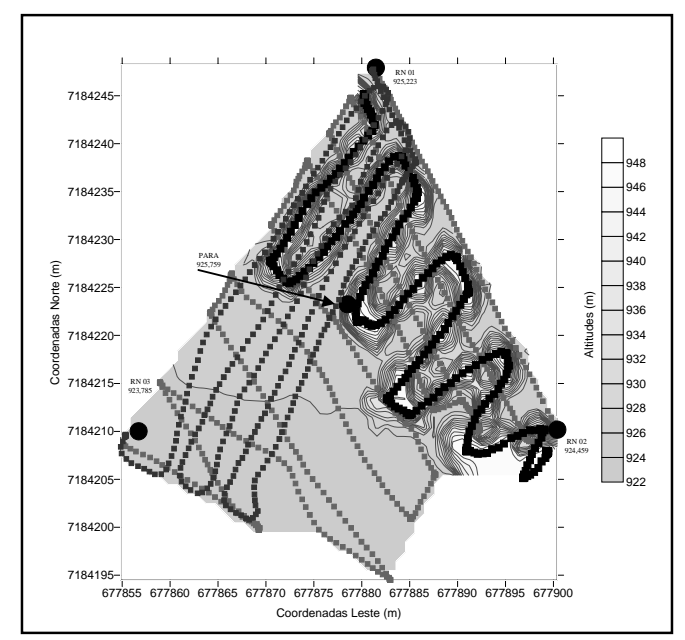

Figura 3 - Isolinhas geradas a partir da grade delimitada para os 3 levantamentos 


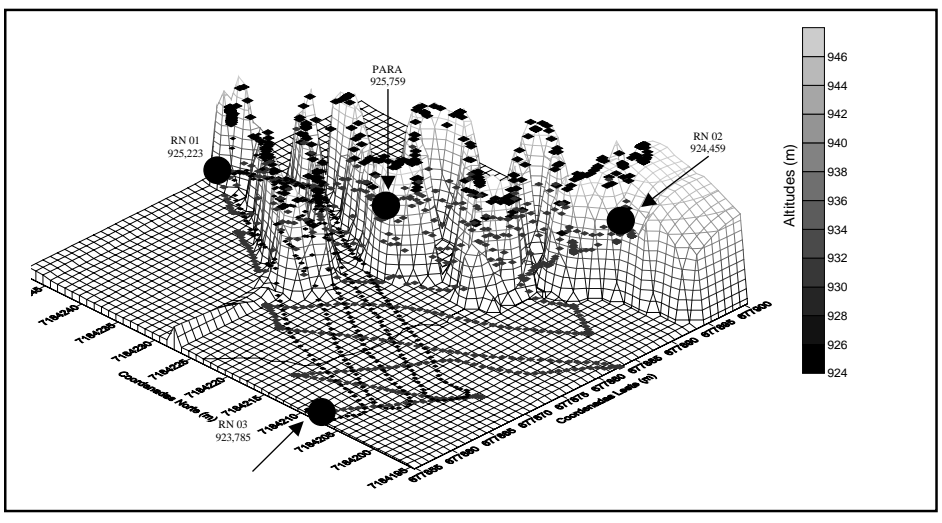

Figura 4 - MDT gerado a partir da grade delimitada para os 3 levantamentos

\subsection{Interpolação Mediante a Técnica de RNA}

Para a interpolação dos modelos por RNA, utilizou-se o programa MatLab 5.3, que possui um aplicativo de RNA, denominado de Neural Network Toolbox for Use in MatLab. A grande flexibilidade na manipulação e formatação de arquivos e diversidade de algoritmos implementados eficiententemente (funções de ativação e transferência) justificam a escolha deste programa nesta pesquisa.

\subsubsection{Treinamento}

Um conjunto de elementos amostrais foram escolhidos para o treinamento da rede. Analisando os dados dos levantamentos $\left(\mathrm{L}_{1} \mathrm{~L}_{2}\right)$; $\left(\mathrm{L}_{1}\right)$; (Código) bem como as RRNN existentes na área de estudo, verificou-se visualmente quais os pontos que representam as nuances mais significativas do relevo, ou seja, aqueles com cotas mais altas e mais baixas, bem como, as intermediárias. Assim estes pontos foram admitidos como as amostras de treinamento da RNA, perfazendo um total de 230 coordenadas. Para $\mathrm{L}_{1} \mathrm{~L}_{2}$ um total de 118 elementos amostrais foram coletados, para $\mathrm{L}_{1}, 44$ e para CA, 68 respectivamente.
A quantidade de amostras foi definida experimentalmente a partir de testes preliminares, que comprovaram que com uma quantidade menor de amostras de treinamento e uma má disposição das mesmas no terreno não é possível atingir um bom aprendizado da rede. Tal fato foi verificado por meio das diferenças das médias e desvios padrão, resultantes entre as coordenadas de verificação, escolhidas a priori, as quais não entraram no treinamento da rede, com as saídas interpoladas fornecidas pela rede.

Para o treinamento das amostras, processadas com a técnica da RNA, temse a necessidade de que estas sejam intercaladas por coordenadas e por tipo de levantamentos, para que o processo de treinamento não se torne tendencioso, isto é, que a modelagem da rede só identifique as características de um conjunto de amostras, ou seja, para que a rede não "decore" mas "aprenda" a identificar determinadas características.

Portanto, as coordenadas foram alternadas. Por exemplo, para $\mathrm{L}_{1} \mathrm{~L}_{2}$ (118 elementos amostrais), foram organizados $\mathrm{em} \approx 13$ vetores, intitulados de $(\mathrm{V})$ com 9 elementos em cada vetor denominados de (A). Para $\mathrm{L}_{1}$ (44 elementos amostrais), foram organizados $\approx$ em 11 vetores $(V)$ com 4 elementos (B) em cada vetor e para o CA (68 elementos amostrais), foram organizados $\approx$ em 17 vetores $(\mathrm{V})$ com 4 elementos $(\mathrm{C})$ em cada vetor.

Por meio do Quadro 1 verifica-se a situação de como as amostras seriam apresentadas a rede sem serem intercaladas e como são, na realidade, intercaladas no estudo. Uma rotina em MatLab foi desenvolvida para realizar esta alternância. 
Quadro 1 - Amostras sem alternância e alternadas

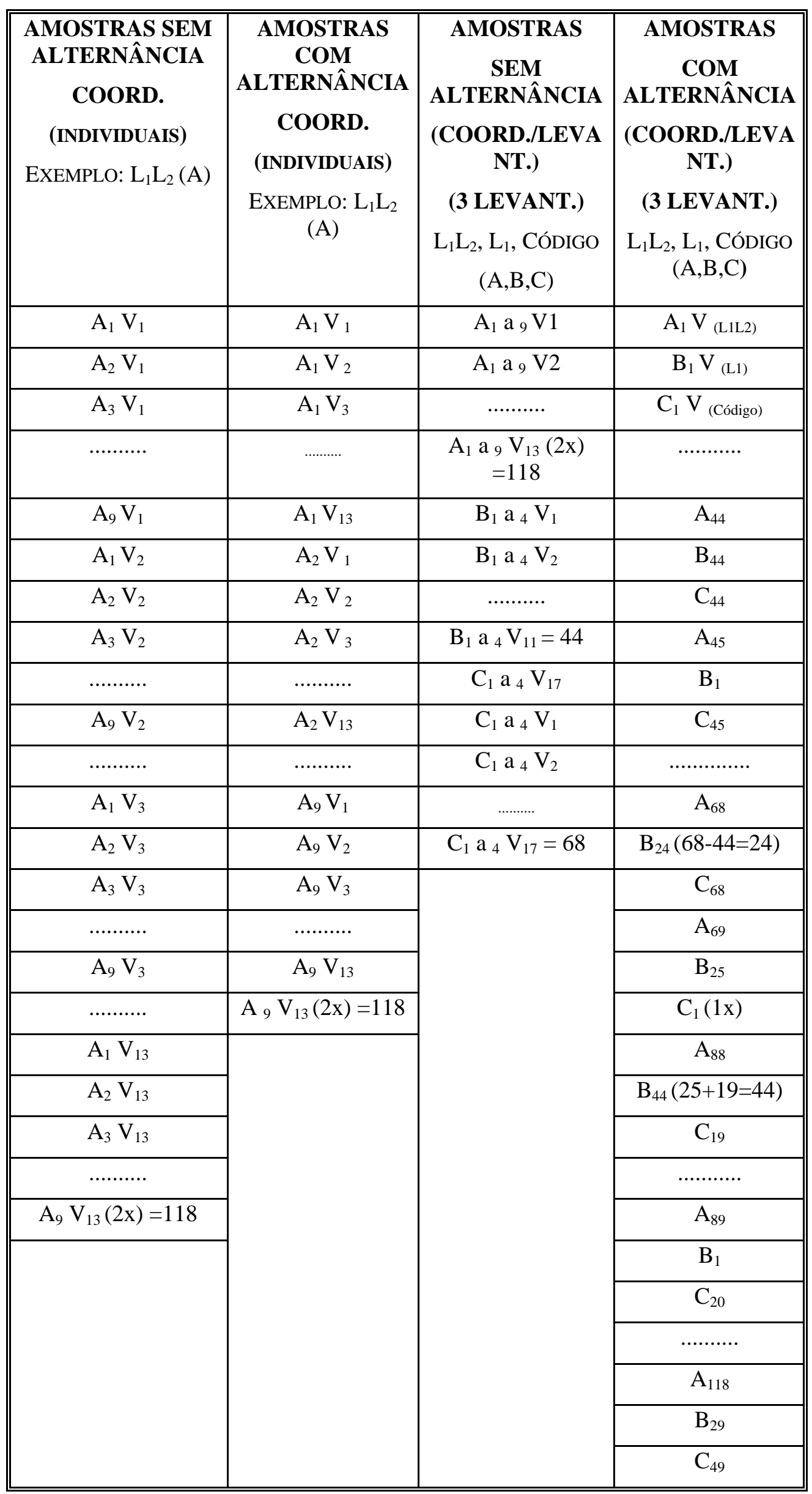




\subsubsection{Arquitetura e Algoritmo de Treinamento da RNA}

Estruturar a arquitetura de uma RNA consiste em definir o número de camadas escondidas e a quantidade de neurônios por camada. Esta definição foi realizada por meio de uma série de experimentos, nos quais a arquitetura foi variada até que foi encontrada a arquitetura ideal.

Ressalta-se que o algoritmo de treinamento utilizado foi o Backpropagation com a variação Resilient Propagation (RPROP), desenvolvido por (REIDMILLER; BRAUN, 1993, p. 586591).

A rede foi treinada com duas e três camadas escondidas, com o intuito de se obter um Erro Médio Quadrático (EMQ) aceitável $(\approx 0,001)$. O mesmo foi adotado tendo em vista a precisão do levantamento, isto é, da ordem centimétrica $\left(\mathrm{L}_{1} \mathrm{~L}_{2}\right)$ e $\left(\mathrm{L}_{1}\right)$ e métrica (CA). Para a maioria dos testes adotou-se um EMQ de 0,001, mas testes com 0,0001 também foram realizados e as épocas/iterações para convergência da rede foram cerca de no máximo 1 minuto de processamento computacional.

Tendo-se definido a quantidade de camadas escondidas foi necessário determinar, experimentalmente, o número de neurônios (nós) por camada. Para tanto, se considera a regra de HILTON (1989), In: FITZGERALD e LEES (1996, p. 984), isto é, para definir o número de nós que as camadas intermediárias da rede devem ter. $\mathrm{O}$ autor afirma que o número de nós desta camada não deve exceder um terço (1/3) do conjunto de amostras de treinamento.

Fixou-se à quantidade de neurônios da primeira camada escondida em $1 / 3$ da quantidade de amostras de treinamento. Variou-se à quantidade de neurônios para a segunda camada, até obter-se uma quantidade de nós, nessa camada, que fornecesse o resultado esperado, em termos de iterações e do erro médio quadrático mínimo estipulado, a qual correspondeu a 1/4 do total de amostras da primeira camada escondida.
Os experimentos realizados utilizando esta arquitetura convergiram com um número baixo de iterações, em torno de 26 épocas, e com um erro médio mínimo quadrático aceitável (performance/erro médio quadrático de 0,00099979 para o critério de parada de treinamento de 0,001 .

Foram realizados dois experimentos para o treinamento da RNA: O primeiro consistiu em treiná-la apenas com as variáveis de entrada $\mathrm{E}, \mathrm{N}$ com diferentes precisões; $\mathrm{O}$ segundo, aproveitando a capacidade da RNA em integrar dados de diferentes fontes, foi adicionada uma nova variável de entrada denominada "pesos" a cada levantamento realizado conforme sua precisão.

Os pesos foram atribuídos conforme as precisões dos levantamentos, desta forma, para os levantamentos $\mathrm{L}_{1} \mathrm{~L}_{2}$, atribuíram-se pesos $(0,8)$, para os levantamentos $L_{1}(0,5)$ e para o Código $(0,2)$. Foram adotados estes valores para que não fosse necessário realizar a normalização dos dados, ou seja, valores estes entre 0 e 1 . Seguindo o critério de que o levantamento menos preciso possui peso menor e o levantamento mais preciso, peso maior nas suas respectivas coordenadas.

\subsubsection{Generalização}

Após o treinamento é efetuada a generalização do treinamento mediante a aplicação do modelo matemático a todos os dados originais, não apenas aqueles usados no treinamento.

Para visualização qualitativa dos resultados obtidos pela RNA utilizou-se o software Surfer, fazendo uso do algoritmo do Vizinho mais Próximo para visualização da grade gerada pela RNA. Optou-se por esse método para gerar as isolinhas e o MDT, pelo fato que os resultados fornecidos pela RNA já são valores interpolados.

O Vizinho mais Próximo é então o mais indicado, pois não interfere nos resultados interpolados pela rede, na etapa de geração da grade, pois o algoritmo parte do critério que a partir de um 
conjunto de amostras e dentro de um raio definido, ele medirá as distâncias e adotará a amostra mais próxima, sem efetuar qualquer ponderação nas coordenadas.

As Figuras 5 e 6 mostram o resultado do processamento da RNA, mediante a geração das isolinhas e do MDT, bem como a trajetória percorrida nos três levantamentos e a localização das RRNN.

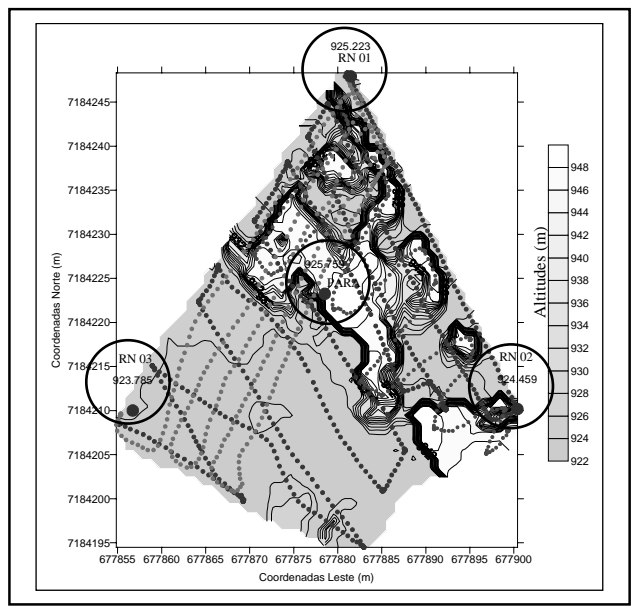

Figura 5 - Isolinhas - saídas RNA

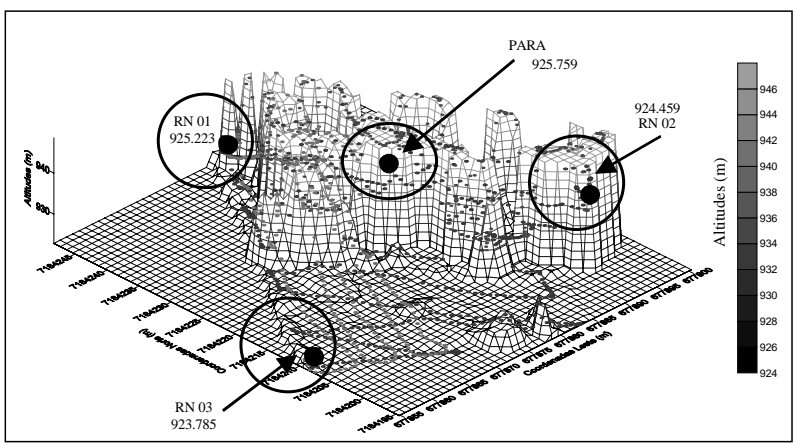

Figura 6 - MDT - saídas RNA

\section{RESULTADOS E DISCUSSÕES}

Com o intuito de uma análise quantitativa dos dados, computou-se a diferença entre as altitudes dos dados de verificação e as saídas interpoladas pela RNA. Com estes resultados foi possível derivar medidas estatísticas que permitem a análise da qualidade da grade gerada com relação aos dados originas de verificação. Segundo GEMAEL (1994, p. 87), a média aritmética é um estimador eficiente e um ótimo estimador da média populacional. Desta forma, escolhida a média aritmética como representativa da grandeza medida através de observações não correlacionadas de mesma confiança restou estimar o seu grau de precisão. Para tanto é necessário adotar-se uma estimativa da precisão das observações, que neste trabalho foi o desvio padrão (medida de dispersão).

Verifica-se, no Quadro 2 os valores residuais da interpolação obtidos para a grade gerada com os três levantamentos com o uso da RNA integrando os levantamentos com diferentes precisões sem a variável “peso”. Também são mostrados os valores residuais da grade gerada com o interpolador IQD.

Quadro 2 - Análise comparativa da interpolação (IQD) e (RNA) (sem variável de entrada peso)

\begin{tabular}{|c|c|c|}
\hline Método & $\begin{array}{c}\text { Inverso do } \\
\text { Quadrado de } \\
\text { uma Distância }\end{array}$ & $\begin{array}{c}\text { Redes } \\
\text { Neurais } \\
\text { Artificiais }\end{array}$ \\
\hline $\begin{array}{c}\text { Total de Elementos } \\
\text { Amostrais }\end{array}$ & 1678 & 1678 \\
\hline $\begin{array}{c}\text { Média das diferenças } \\
(\mathrm{m})\end{array}$ & 0,5951 & 0,0745 \\
\hline $\begin{array}{c}\text { Desvio padrão das } \\
\text { diferenças(m) }\end{array}$ & 0,1049 & 0,1035 \\
\hline
\end{tabular}

Comparando-se os valores das colunas do Quadro 2, pode-se verificar que quando os três levantamentos foram processados juntos tanto pelo IQD como pela RNA (sem a atribuição da variável de entrada "pesos"), o desvio para a grade delimitada no primeiro caso foi $10,49 \mathrm{~cm}$ e no segundo caso $10,35 \mathrm{~cm}$, ou seja, uma diferença de $0,14 \mathrm{~cm}$. Observa-se que a RNA executa o mesmo processo do IQD com a mesma precisão.

Verifica-se no Quadro 3 os valores residuais obtidos para as grades geradas a partir das coordenadas de saída que a RNA forneceu na integração dos dados GPS de diferentes precisões, quando a variável de entrada "pesos" foi utilizada no treinamento da rede. 
Quadro 3 - Análise comparativa da integração (IQD) e (RNA) (com variável de entrada peso)

\begin{tabular}{|c|c|c|}
\hline Método & $\begin{array}{c}\text { Inverso do } \\
\text { Quadrado de } \\
\text { uma Distância }\end{array}$ & $\begin{array}{c}\text { Redes } \\
\text { Neurais } \\
\text { Artificiais }\end{array}$ \\
\hline $\begin{array}{c}\text { Total de Elementos } \\
\text { Amostrais }\end{array}$ & 1678 & 1678 \\
\hline $\begin{array}{c}\text { Média das diferenças } \\
(\mathrm{m})\end{array}$ & 0,5951 & 0,3437 \\
\hline $\begin{array}{c}\text { Desvio padrão das } \\
\text { diferenças(m) }\end{array}$ & 0,1049 & 0,0618 \\
\hline
\end{tabular}

Quando a integração dos dados foi efetuada na etapa de processamento da rede atribuindo os pesos, de acordo com as precisões dos levantamentos, obteve-se bons resultados (Quadro 3), comparativamente com o interpolador IQD.

Observando-se os Quadros 2 e 3 para os resultados da RNA, nota-se que a média da diferença entre a grade gerada e os pontos de verificação aumentaram de 0,0745 para 0,3437 . Este fato ocorre devido a grade gerada ter sido comparada com pontos de verificação que também contém pontos pertencentes ao levantamento código (precisão métrica). Sendo que no segundo caso, a RNA foi processada dando pesos ao código $(0,2)$, ou seja, fazendo com que o código não tenha muita influência na grade final, assim gerando-se uma superfície mais influenciada por levantamentos com precisões centimétricas $\left(\mathrm{L}_{1} \mathrm{~L}_{2}, \mathrm{~L}_{1}\right)$.

Comparativamente verifica-se que os desvios padrão do Quadro 2, para a grade gerada pela RNA sem o uso da variável de entrada "pesos", foram de $10,35 \mathrm{~cm}$. Utilizando-se desta variável, passaram a ser de 6,18cm (Quadro 3), isto é, uma diferença de $4,17 \mathrm{~cm}$ entre as grades geradas sem e com a atribuição dos pesos, mostrando o melhor desempenho da RNA.

\section{CONSIDERAÇÕES FINAIS}

Conclui-se que o desempenho das redes foi superior ao método de interpolação IQD, pois forneceu melhores resultados, principalmente na etapa de integração, quando as verificações e análises mediante as isolinhas e o MDT bem como na análise dos resíduos.

A atribuição dos pesos nas coordenadas é indicada quando se deseja processá-los em conjunto, principalmente se possuírem precisões diferentes, neste caso centimétricas $\left(\mathrm{L}_{1} \mathrm{~L}_{2}, \mathrm{~L}_{1}\right)$ e métricas (Código), para obtenção de valores mais significativos na etapa de integração dos dados.

A metodologia de integração foi satisfatória, mostrando que se a rede tiver mais uma variável de entrada, neste caso as precisões dos levantamentos (denominada de pesos) e se forem bem treinadas, aprendem mais sobre as características do relevo, conseqüentemente, consegue generalizar para todo o conjunto de dados, fornecendo uma saída mais precisa.

\section{REFERÊNCIAS BIBLIOGRÁFICAS}

FITZGERALD, R. W.; LEES, B. G. Temporal Context in Floristic Classification. Computers Geosciences, v. 22, n. 9, pp. 981- 994, 1996.

GEMAEL, C. Introdução ao Ajustamento de Observações. Curitiba: Editora da UFPR, 319 p.,1994.

\section{HILTON G. E. Connections Learning} Procedures. Artificial Intell, v. 40, n.1-3, pp. 185 - 234, 1989.

REIDMILLER, M.; BRAUN, H. A Direct Adaptive Method for Faster Backpropagation Learning: The RPROP Algorithm. In: Proceedings of the IEEE, International Conference on Neural Network (ICNN), San Francisco USA, pp. 586 - 591, 1993.

SOUZA, E. C. B. Análises Temporais de Alta Precisão Utilizando GPS para Avaliação das Variações Volumétricas Ocorridas no Istmo da Ilha do Mel. Dissertação (Mestrado em Ciências Geodésicas). Departamento de Geomática. Universidade Federal do Paraná, Curitiba, 2002. 149 p. 